\title{
VEGETATION INDEX BASED IN UNMANNED AERIAL VEHICLE (UAV) TO IMPROVE THE MANAGEMENT OF INVASIVE PLANTS IN PROTECTED AREAS, SOUTHERN BRAZIL.
}

\author{
C.L. Mallmann ${ }^{12}$, A.F. Zaninni', W. Pereira Filho' \\ ${ }^{1}$ Dep. of Geosciences, Federal University of Santa Maria, Roraima Avenue, Santa Maria, RS, Brazil - afzanini@bol.com.br; \\ waterloo@ufsm.br \\ ${ }^{2}$ State Secretary of environment and infrastructure, RS, Brazil - carolinemallmann15@gmail.com
}

KEY WORDS: Remotely Piloted Aircraft Systems (RPAs); drone; alien plants; multispectral camera; vegetation index;

\begin{abstract}
:
The biological invasion is considered the second largest global threat to the maintenance and conservation of natural ecosystems biodiversity. Strategies and actions that guide the control and monitoring of invasive species in protected areas are still a challenge on the management of these areas. Remote sensing is potential tool to detect and monitoring these species, gaining a timeline scale and allowing the adoption of more effective control methods. In this study, search to evaluate the vegetation index potential by using multispectral images acquired by UAV as a support on detection and monitoring of invasive plants in Quarta Colônia State Park located on the Brazil's southern region. A sampling area with a density of invasive plants above $80 \%$ was evaluated, with predominance of Psidium guajava and Ligustrum lucidum, generating a large data set from the extracted indexes. Among the evaluated index, the ones that showed the most potential in this study were Green Normalized Difference Vegetation Index (GNDVI), Plant Senescence Reflectance Index (PSRI) and Red Green Ratio Index (RGRI). Believe us that the use of UAVs platforms will be an important tool for the management of invasive species in protected areas.
\end{abstract}

\section{INTRODUCTION}

Until the end of $20^{\text {th }}$ century the monitoring by images was a difficult task to researchers due to the shortage and high cost of equipment and technology based. On the first two decades of $21^{\text {th }}$ century the scientific and technological development approached the technology to the users, turning the use of these tools on something practicable. The multispectral remote sensing systems register the energy in different intervals of electromagnetic spectrum (Jensen, 2009) allowing the obtaining of data about biophysical and biochemical parameters of the vegetation for the forestry studies.

Invasive species represent the second largest threat to the biodiversity losing only to the fragmentation of habitats (Wilcove et al., 1998) and are a great challenge to the management of protected areas (Allen et al., 2009). Disturbed ecosystems associated to the distinct uses of the soil around the protected areas, provide seed propagation for the colonization of these natural environment, leading to the establishment and success of the invasion (Stadler et al., 2000; Stohlgren, 2002). The management of protected areas still lacks of better strategies to the eradication, control and mitigation of damage caused by invasive species (Foxcroft et al., 2009). In this sense, the remote sensing has shown potential to identify and manage areas contaminated by invasive plants, contributing to the management and efficiency of control actions.

Dash et al. (2019) evaluated by remote detection invasive coniferous trees, using high resolution data from sensors attached to Unmanned Aerial Vehicle (UAVs). In addition, these platforms has shown their potential for a large amplitude of environmental applications include specific studies to map, quantify and monitor wood plants (Baena et al., 2018), allow to generate important data in a short time, like the vegetation index that enable to analyze the forestry dynamics and behavior, obtaining more precisely diagnosis (Dash et al., 2017).

Therefore, this study has the objective to evaluate in a first approach a vegetation indexes potential extracted from multispectral images based on UAVs as a support in the detection to management of invasive species.

\section{MATERIALS AND METHODS}

\subsection{Study area}

The Quarta Colônia State Park is located on the central region of the Rio Grande do Sul State, southern Brazil, and has a total area of 1.847 hectares. The predominant vegetation is the subtropical seasonal forest, as part of the Atlantic Forest Biome. Around $30 \%$ of the area is classified as a degraded area, a situation that derives of the historic use of the soil, focus of the concentration of invasive species (Mallmann et al., 2015).

In the Park were registered a total of 22 species of invasive plants in the area defined as priority for the management actions comprehends about 120 hectares that overlaps to the degraded areas and the borders of the forest and rivers, systematized by a grid $(100 \mathrm{~m} \times 100 \mathrm{~m})$ as shown in Figure 1 . 


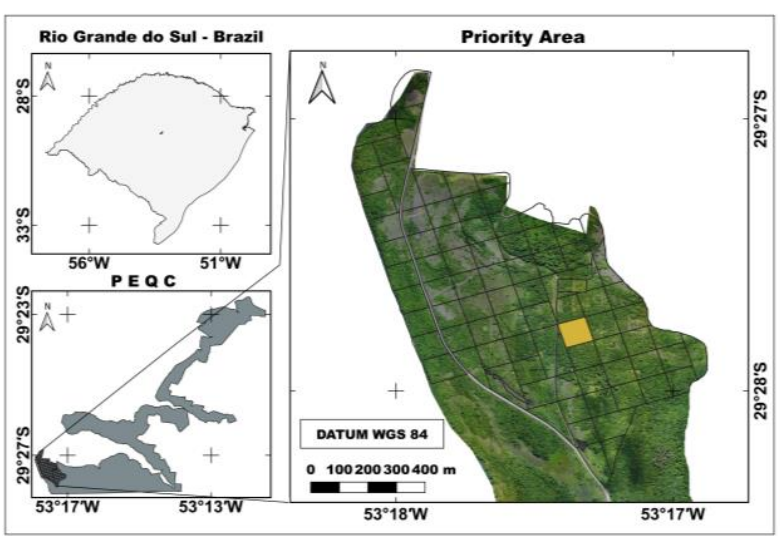

Figure 1. Quarta Colônia State Park location.

\subsection{Invasive Plant Data.}

The sampling was performed in the priority area for the management of invasive species. Ligustrum lucidum; Psidium guajava and Tecoma stans are the invasive plants established in the area. A sample area of 1.0 ha was selected for the analysis and processing of the indices. The selected area presented predominance of invasive species with Absolute Density (AD) of 3.400 individuals / ha and Relative Density (RD) of $48 \%$ for Psidium guajava; $44 \%$ for Ligustrum lucidum and $8 \%$ distributed among other species.

\subsection{Image Acquisition}

Researches in the environmental area were improved with the use of imaging performed by sensors integrated with UAVs. These aircrafts started to be developed about a century ago for war purposes, but with the recent decades' technological revolution, they have become an accessible instrument to researchers and consumers because of their characteristics and capabilities. The reduced size and weight of the imaging sensors allowed their transportability and integration with UAVs, which are popularly known as drones. The possibility of generating images in a short period and the fast processing allows the frequent and detailed monitoring of environmental changes in moments of non-coverage by satellite images (Longhitano, 2010).

For the current research, it was used a DJI Phantom 4 (Advanced) multirotor with a Parrot Sequoia multispectral sensor and a GPS / IMU magnetometer solar sensor with the following characteristics: $1280 \times 960$ pixels / VAF: $61.9^{\circ} /$ VFOV: 48, $5^{\circ}$ /DFOV: 73.7 (Figure 2).

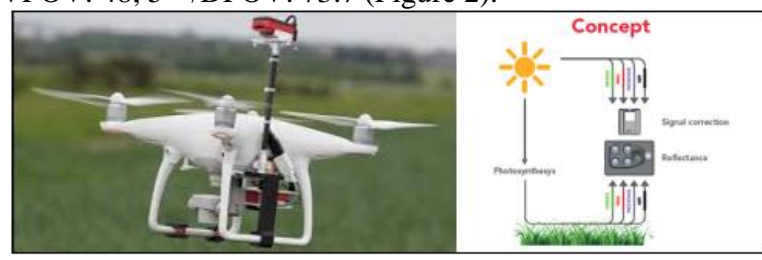

Figure2. Drone Phantom 4 Advanced with integrated Parrot sequoia camera.

To obtain the digital data presented in this work, the images generated by the four spectral intervals of the Parrot Sequoia camera were used, as described in Table 1. The aerial survey was carried out in an area of 134 ha on 11/03/2019, starting at 09:11 and end at 13:42, with total tracking time of 04:30 hours. At the time of imaging, the sky was sunny, cloudless and virtually windless.

\begin{tabular}{|l|l|}
\hline Spectral range & Wavelength range (nm) \\
\hline Green & $430-470$ \\
\hline Red & $640-680$ \\
\hline Red-Edge & $730-740$ \\
\hline Near Infrared & $770-810$ \\
\hline
\end{tabular}

Table 1. Spectral range Parrot Sequoia.

\subsection{Vegetation Indexes Processing}

The selected vegetation index for the current study was Anthocyanin Content Index (ACI), Anthocyanin Reflectance Index (ARI), Green Normalized Difference Vegetation Index (GNDVI), Normalized Difference Vegetation Index (NDVI), Plant Senescence Reflectance Index (PSRI) and Red Green Ratio Index (RGRI). The selected indexes connect structural, physiological and biochemical aspects of the vegetation to evaluate a possible relation with invasive exotic species (Table 2).

\begin{tabular}{|l|l|c|}
\hline \multicolumn{1}{|c|}{ INDEX } & AUTHOR & EQUATIONS \\
\hline ACI & $\begin{array}{l}\text { Van de Berg e } \\
\text { Perkins (2005) }\end{array}$ & $\frac{\text { Rgreen }}{\text { RNIR }}$ \\
\hline ARI & $\begin{array}{l}\text { Gitelson, et al. } \\
(2001)\end{array}$ & $\frac{1-\text { Rgreen }}{1-\text { Rred_edge }}$ \\
\hline GNDVI & $\begin{array}{l}\text { Gitelson et } \\
\text { al.(1996) }\end{array}$ & $\frac{\text { RNIR - Rgreen }}{\text { RNIR + Rgreen }}$ \\
\hline NDVI & $\begin{array}{l}\text { Rouse et al. } \\
\text { (1974) }\end{array}$ & $\frac{\text { RNIR - Rred }}{\text { RNIR + Rred }}$ \\
\hline PSRI & $\begin{array}{l}\text { Merzlyak } \\
\text { al.(1999) }\end{array}$ & $\frac{\text { Rred - Rgreen }}{\text { Rred_edge }}$ \\
\hline RGRI & $\begin{array}{l}\text { Gamon e Surfus } \\
\text { (1999) }\end{array}$ & $\frac{\text { Rred }}{\text { Rgreen }}$ \\
\hline
\end{tabular}

Table 2. Vegetation index used in the study.

The sample portion of the experiment comprehends an area of 1.0 ha (Figure 3 ) highlighted by a RGB image obtained by the camera integrated with the UAV Phantom 4 at the same time that the sensing with the Parrot Sequoia Camera was performed. Both sensors were used simultaneously, operated by independent software and controllers.

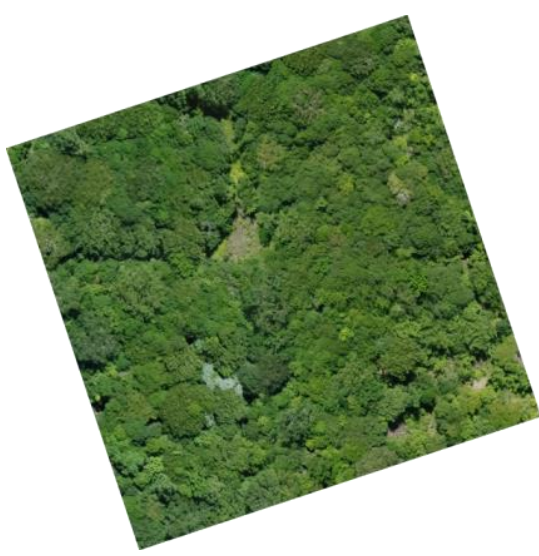

Figure 3. RGB color image to the sample area.

The indexes were calculated from images generated by the Parrot Sequoia sensor and over a previously selected area that 
covers a representative sample of the biological invasion situation (Figure 4). The calculation was performed using the "Raster Calculator" tool of the QGIS software, where the formulas for each index were inserted. Afterwards, the respective values were extracted with the "Raster Converter" tool, transforming the raster image into pixel values in CSV format. After completing the step, the "Plugin r.to.vect" was used to read the pixel values point by point, resulting in 500,000 data per generated index. Lastly, were performed the statistical analysis.

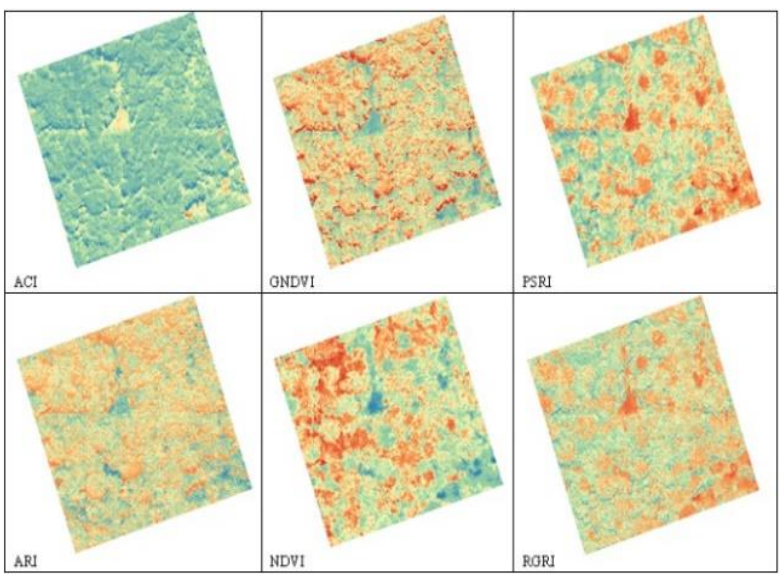

Figure 4. False color image attributed to the index vegetation calculated for the sample area.

\section{RESULTS AND DISCUSSION}

A data exploratory analysis allowed us to identify the patterns for each index (Table 3). In general, the indexes presented low amplitude, except for RGRI and NDVI. GNDVI presented the lowest coefficient of variation (CV\%) for the analyzed data set.

\begin{tabular}{|l|r|r|r|r|l|l|}
\hline & \multicolumn{1}{|l|}{ ACI } & \multicolumn{1}{l|}{ ARI } & GNDVI & NDVI & PSRI & RGRI \\
\hline Ave & 0,003 & 0,011 & 0,993 & 0,282 & $-0,002$ & 0,678 \\
\hline Max & 0,014 & 0,499 & 0,999 & 0,511 & 0,001 & 1,24 \\
\hline Min & 0,001 & 0,004 & 0,972 & $-0,436$ & $-0,005$ & 0,024 \\
\hline Mod & 0,002 & 0,009 & 0,994 & 0,244 & $-0,001$ & 0,666 \\
\hline Med & 0,003 & 0,009 & 0,994 & 0,298 & $-0,002$ & 0,699 \\
\hline SD & 0,001 & 0,007 & 0,002 & 0,0999 & 0,001 & 0,129 \\
\hline CV\% & 43,34 & 63,27 & 0,269 & 35,398 & $-33,33$ & 19,09 \\
\hline
\end{tabular}

Table 3. Descriptive statistics of index.

NDVI is the most known and widely used index with values between 0,2 and 0,9 for green vegetation, being expanded in favor of low biomass conditions and compressed under high biomass conditions (Jensen, 2009). In the studied area, NDVI presented a great amplitude ranging from $-0,44$ to 0,51 , and presented 0,2 as a central tendency measure. The presented amplitude is attributed to the image high resolution, as well as to the analyzed phenological period characterized by low vegetative growth. When correlate NDVI with GNDVI, an index is developed to estimate the plant chlorophyll content (Gitelson et al, 1996; Hunt et al., 2008). NDVI and GNDVI present a correlation higher than $90 \%$, although GNDVI has high values, around 0,99 , and low coefficient of variation.

The ACI and ARI indexes showed a high correlation (88\%), but with median and mode values close to zero, demonstrate low sensitivity for the proposed study, for the sake of the used sensor and type of analysis performed. However, the maximum peaks presented by the ARI should be considered. Such peaks reached 0,49 and with $63 \%$ of coefficient of variation. The indexes are based on absorption spectra and on anthocyanins content estimation, pigment related to stressed and senescent leaves (Gitelson et al., 2001). They should be tested at leaf level and individualized by species because there is a lack of specific biochemical and biophysical information on the target species selected for this study.

In general, indexes with biochemical purposes proved to be more promising for the study with invasive species such as GNDVI, PSRI and RGRI (Figure 5).

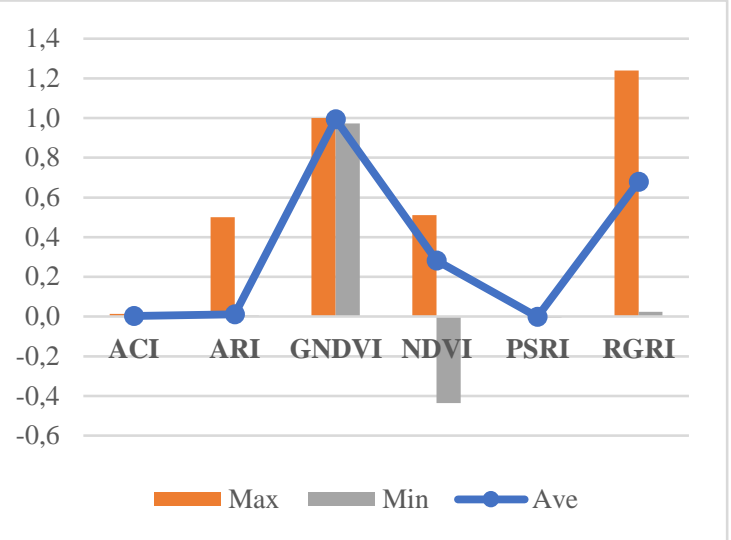

Figure 5. Distribution of values for index.

The PSRI was proposed to increase the sensitivity of the carotenoids ratio in relation to chlorophyll. An increase in PSRI indicates an increase in canopy stress or highlights the beginning of senescence period (Zhou et al., 2017). The values for this index range from -1 to 1 , with the common range of values for green vegetation being between -0.1 to 0.2 (MERZLYAK et al., 1999). Data showed values between -0.1 and 0.1 , in other words, the index is in agreement with the type of vegetation analyzed because the predominant invasive species in the place, Psidium guajava and Ligustrum lucidum, have leathery green leaves and are not deciduous despite the phenological period of the analysis matched the beginning of leaf senescence. Invasive species have great competitive advantage and adaptive mechanisms that lead to a successful invasion. In this context, the PSRI, based on caratenoid estimates, can have a good performance when applied to compare preserved forest areas with native species predominance in the same phonological period.

The RGRI is a proposed index to estimate and distinguish divergent patterns of pigment activity (anthocyanin) and is directly related to leaf structure, light regimes and functional type (Gamon, JA, \& Surfus, JS, 1999). In the studied area, values between 0,02 and 1,24 were obtained with low dispersion and coefficient of variation of $19 \%$. Differently from the values obtained for ACI and ARI indexes, the RGRI was more sensitive to the application in the present study. However, as well as other tested indexes, RGRI is well understood at the leaf level, but there is a lack of an analytical model responsible to quantify anthocyanin and carotenoid content in canopy or support scales.

The use of aircraft and image spectrometers to detect and map pigments is new, but the image spectroscopy potential to detect and quantify leaf pigments for physiology studies and canopy ecology is recognized (Ustin, et al., 2009), enhance possibilities with the popularization of multispectral sensors coupled to UAVs because of scale refinement. 


\section{CONCLUSIONS}

In this work, it was evaluated the potential of data acquisition for vegetation index generation from images obtained by a multispectral sensor coupled to a UAV platform and its possible application as a support in the detection and control of areas contaminated by invasive plants. The high spatial resolution of the acquired data provides very accurate information about vegetation and can be applied at species level.

Target-specific studies exploring biochemical and biophysical variables are needed to advance UAV-based spectroscopy for more reliable information. Such studies have already been carried out on site, on species of interest, to support the use of remote sensing techniques. However, for a first exploratory analysis of vegetation indexes, it is possible to assess the potential of the sensor regarding its sensitivity for indexes that relate physiological and ecological aspects of the canopy.

Moreover, it should be noticed that the vegetation indexes standardization for species of interest is an important tool to enable applied studies of detection and monitoring in conservation areas and forest management, besides helping the management team to take decisions.

\section{ACKNOWLEDGEMENTS}

Acknowledgements of support for the project from the State Secretary of environment and infrastructure of RS, Brazil and Group CPFL Energy.

This study was financed in part by the Coordenação de Aperfeiçoamento de Pessoal de Nível Superior - Brasil (CAPES) - Finance Code 001.

\section{REFERENCES}

Allen, J.A., Brown, C.S. \& Stohlgren, T.J.2009.Non-native plant invasions of United States National Parks. Biol Invasions, 11: 2195 .

Baena, S.; Body, S.D.; Moat, J. UAVs in pursuit of plant conservation - Real world experiences. Ecological informatics.2018, 47,2-9.

Dash, J. P., Watt. M. S., Pearse, G. D., Heaphy, M., Dunguey. H. J. 2017. Assesing very high resolution UAV imagery for monitoring forest health during a simulated disease outbreak. ISPRS Journal of Photogrammetry and Remote Sensing. 131, $1-14$.

Dash, J.P.; Watt, M.S.; Paul, T.S.H.; Morgenroth, J.; Pearse, G.D. 2019 Early Detection of Invasive Exotic Trees Using UAV and Manned Aircraft Multispectral and LiDAR Data. Remote Sensing. 11, 1812.

Foxcroft, L.C; Richardson, D.M; Rouget, M.; Macfadyen, S. 2009. Patterns of alien plant distribution at multiple spatial scales in a large national park: implications for ecology, management and monitoring. Diversity and Distributions, (Diversity Distrib.)15, 367-378.
Gamon, J. A., Surfus. J. A.,1999. Assessing leaf pigment content and activity with a reflectometer. New Phytol. 143, 105-117.

Gitelson, A.A, Kaufman, Y.J., Merzlyak, M.N. 1996. Use of a green channel in remote sensing of global vegetation from EOS-MODIS. Remote Sensing of Environment. Vol.58, 289298.

Gitelson, A. A., Merzlyak, M. N., Chivkunova, O. B.; 2001. Optical properties and destructive estimation of anthocyanin contente in plant leaves. Photochem. Photobiol. 74. 38-45.

Hunt, E. R. et al.2008. Remote Sensing of Crop Leaf Area Index Using Unmanned Airborne Vehicles. Pecora 17 - The future of land imaging.

Jensen, J.R. 2009. Sensoriamento Remoto do ambiente: uma perspectiva em recursos terrestres, $2^{\circ}$ ed. São José dos Campos, SP: Parêntese, 672 p.

Longhitano, G.A. VANTs para sensoriamento remoto: aplicabilidade na avaliação e monitoramento de impactos ambientais causados por acidentes com cargas perigosas. Escola Politécnica da Universidade de São Paulo. Ed.rev. Saõ Paulo, 2010. 148p.

Mallmann, C. L; Prado, D.A; Pereira Filho, W. 2015. Índice de vegetação por diferença normalizada para caracterização da dinâmica florestal no parque estadual Quarta Colônia, estado do Rio Grande do Sul - Brasil. Revista Brasileira de Geografia Física, Pernambuco, v.08, n. 05, p. 15.

Merzlyak, M. N., Gitelson, A. A., Chivkunova, B. O., Rakitin. V. Y. 1999. Non- destructive optical detection of leaf senescence and fruit ripening. Physiol . Plant. 106, 135-141.

Stadler, J; Trefflich, A.; Klotz, S.; Brandl, R. 2000. Exotic plant species invade diversity hot spots: the alien flora of northwestern Kenya. Ecography 23:169-176.

Stohlgren, T.J. 2002. Beyond theories of plant invasions: lessons form natural landscapes. Comments Theor Biol 7:355379 .

Ustin, S.L.; Gitelson, A.A. Jacquemoud, S.; Schaepman, M.; Asner, G.P. Asner; Gamon, J.A; Zarco-Tejada, P.2009. Retrieval of foliar information about plant pigment systems from high resolution spectroscopy. Remote Sensing of Environment 113,67-77

Van den berg, A. K., Perkins, T. D., 2005. Nondestructive Estimation of Anthocyanin Content in Autumn Sugar Maple Leaves Hort Science 40 (3): 685-686.

Wilcove, D.; Rothstein, D.; Dubow, J.; Phillips, A.; Losos, E. 1998. Quantifying Threats to Imperiled Species in the United States. BioScience, 48(8), 607-615.

Zhou, X. et al.2017. Assessment of leaf carotenoids content with a new carotenoid index: Development and validation on experimental and model data. International Journal of Applied Earth Observation and Geoinformation, v. 57, p. 24-35. 